\title{
BASES TEÓRICAS (DOUTRINÁRIAS, LEGAIS E JURISPRUDENCIAIS) DA SOCIOAFETIVIDADE NAS RELAÇÕES DE FAMÍLIA
}

\section{BASIS TEORICAS (DOCTRINARIAS, LEGALES Y JURISPRUDENCIALES) DE LA SOCIOAFETIVIDAD EM LAS RELACIONES DE FAMILIA}

\author{
${ }^{1}$ Denise S. S. Garcia \\ ${ }^{2}$ Marcos Vinícius Viana da Silva
}

\begin{abstract}
RESUMO
O presente artigo tem como tema principal a análise das bases teóricas contidas na doutrina, na lei e em julgados que sejam relacionados com a socioafetividade. O conceito de família ao longo dos tempos sofreu profundas modificações e adaptações, onde não mais importa somente o agrupamento familiar biológico que a pessoa pertença, mas sim, o ambiente que lhe traz felicidade, amor, valores, carinho e respeito. Sob esta ótica, a legislação vem sofrendo modificações e adaptações principalmente no que concerne ao direito de filiação e os desdobramentos da filiação socioafetiva. Portanto, esse artigo terá como objetivo geral analisar o valor jurídico da socioafetividade. Os objetivos específicos são: identificar os elementos caracterizadores do estado de filho afetivo, a irrevogabilidade da filiação socioafetiva, as provas necessárias para o reconhecimento da filiação socioafetiva e sua previsão legal, e verificar a possibilidade do uso do patronímico do padrasto ou da madrasta. Para a elaboração do artigo foi utilizado método indutivo, com as técnicas do referente, das categorias, do fichamento e da revisão bibliográfica.
\end{abstract}

Palavras-chave: Filiação socioafetiva, Família, Socioafetividade

\begin{abstract}
El presente artículo tiene como tema principal el análisis de las bases teóricas contenidas en la doctrina, la ley y juzgados que sean relacionadas con el socio-afectividad. El concepto de familia en los últimos años ha experimentado profundos cambios y adaptaciones, donde no más importa solamente el agrupamiento familiar biológico que la persona pertenece, sino el ambiente que le trae felicidad, amor, valores, cariño y respecto. Desde esta perspectiva, la legislación viene sufriendo cambios y adaptaciones relativas principalmente al derecho a la afiliación y las consecuencias de la afiliación socio-afectiva. Así que este artículo tendrá como objetivo general analizar el valor jurídico del socio-afectividad. Los objetivos específicos son: identificar los elementos característicos de la situación afectiva del niño, la irrevocabilidad de afiliación socio-afectiva, las pruebas necesarias para reconocer la filiación socio-afectiva y su disposición jurídica, y verificar la posibilidad de utilizar el patronímico del padrastro o madrastra. Para la preparación de este artículo se utilizó el método inductivo, con las técnicas de referencia, las categorías, el informe del libro y revisión de la literatura.
\end{abstract}

Keywords/Palabras-claves/Mots-clés: Afiliación socio-afectiva, Familia, Socio-afectividad

\footnotetext{
${ }^{1}$ Doutora em Direito ambiental e sustentabilidade pela Universidade de Alicante, UA, Espanha. Advogada e sócia no escritório Garcia Advocacia, G, Brasil. E-mail: denisegarcia@univali.br.

${ }^{2}$ Doutorando em Ciência Jurídica na Universidade do Vale do Itajaí, UNIVALI, Santa Catarina, SC, Brasil. Advogado no escritório Tussi e Platchek Adovagos Associados, TP, Brasil.E-mail: mvsilva0805@gmail.com.
} 


\section{INTRODUÇÃO}

O Direito de família gravita em outra esfera do Direito em geral, pois lida com relações de afeto e principalmente com direitos de menores, afeto esse que na esteia da evolução e compreensão do Direito de Família recebeu atribuição de um valor jurídico. E é esse sentimento, agora como um novo valor jurídico, que tem desinstalado as velhas concepções e instalado uma nova ordem jurídica para a família.

Nessa órbita dos direitos dos menores, a proteção maior deve ser despendida a eles, no sentido de que todos os atos praticados e interpretações feitas devem ser com o intuito do menor prejuízo ao infante.

Sobre o tema se destaca dos dizeres de Pereira (2006, p.137), ao comentar toda a importância relacionado a formação geral de um indivíduo, "Zelar pelo interesse do menor é cuidar da sua boa formação moral, social e psíquica. É a busca da saúde mental, a preservação da sua estrutura emocional e de seu convívio social".

Da mesma forma, extrai-se da leitura de François Dolto, através de seu "olhar interdisciplinar", a análise e sustentação da disciplina desta matéria através de três referenciais de continuidade:

- O continuum de afetividade;

- O continuum social, que indica a necessidade de preservação do ambiente e do relacionamento social, até então vivido pela criança;

- O continuum espacial, determinando que o espaço da criança deve ser preservado, porque a personalidade do menor é constituída dentre de um certo espaço. Quando há mudança de espaço, do lugar onde vive, pode perder um dos seus referenciais. (PEREIRA, 2006, p. 126)

Diante dessa realidade, é preciso repensar o instituto familiar, considerando que o mais importante são os laços de amor e de afeto que existem entre seus membros, e por consequência deixando de lado alguns pensamentos e preconceitos que não cabem mais na atualidade e no presente mundo do direito.

Assim, o presente artigo tem como objetivo geral analisar o valor jurídico da socioafetividade. E objetivos específicos, identificar os elementos caracterizadores do estado de filho afetivo, a irrevogabilidade da filiação socioafetiva, as provas necessárias para o reconhecimento da filiação socioafetiva e sua previsão legal, e verificar a possibilidade do uso do patronímio do padrastro ou da madrasta. 
A base jurídico argumentativa do presente trabalho se debruça sobre diferentes doutrinas, que oportunamente serão apresentadas na pesquisa, além da jurisprudência pátria, que já revela alguns consideráveis e pertinentes mudanças.

Informa-se ainda dentro da introdução, que o presente artigo fora divido em 8 itens, que respondem especificamente todos os objetivos específicos anteriormente expostos e propostos nesta pesquisa.

Para a elaboração do artigo foi utilizado método indutivo, tanto para coleta dos dados quanto no tratamento dos mesmos durante toda a pesquisa, aplicando técnicas do referente e do fichamento conforme preconiza o doutrinar Pasold (2011) para as análises pertinentes.

\section{O VALOR JURÍDICO DA FILIAÇÃO SOCIOAFETIVA}

A filiação socioafetiva é uma realidade que não pode ser descartada, pois dela decorrem direitos e obrigações, e mais, decorre de amores, verdades, sentimentos, realidades, cumplicidade, referência.

Quando se olha para trás, pode-se até pensar que afeto e direito eram palavras autônomas. Havia um engessamento de questionamentos, onde se dizia diretamente ou entrelinhas: O Direito não pode quantificar o afeto. Não se pode responsabilizar o abandono afetivo. Filhos do amor?! Filho deve ser jurídico, está registrado? (LOMEU, 2015, p. 83)

\footnotetext{
Apesar de sabermos que não basta amoldar a vida à norma; é necessário humanizar o direito e não apenas ver aplicadas as leis, por lidar com a vida das pessoas, seus afetos e suas mágoas, elementos tão íntimos e subjetivos. $\mathrm{O}$ direito deve ser mais célere, menos moroso. O Estado deve assegurar a felicidade, sempre que possível. (LOMEU, 2015, p. 83)
}

Deve também ficar claro que a filiação socioafetiva sempre existiu no seio familiar nas mais variadas situações, como no caso da "filiação afetiva na adoção, filiação sociológica do filho de criação, filiação socioafetiva na 'adoção à brasileira'”. (WELTER, p. 148-150)

Outra forma de filiação socioafetiva existente são as inseminações artificiais heterólogas que são aquelas que ocorrem por meio da doação de sêmen de um homem que não seja o marido, contando com sua concordância, sendo que é obrigatório nesses casos o sigilo sobre a identidade dos doadores e dos receptores.

A fecundação heteróloga gera presunção et de jure, pois não há possibilidade de ser impugnada. Trata-se de presunção absoluta de paternidade socioafetiva. A paternidade 
constitui-se, desde a concepção, no início da gravidez, configurando-se hipótese de paternidade responsável. (DIAS, 2009, p. 336)

Outro destaque que se faz quanto à validade da filiação socioafetiva é a possibilidade que a legislação brasileira concede do pai fazer o registro de seu filho sem ter que comprovar qualquer paternidade biológica, necessitando para tanto, somente comparecer espontaneamente no cartório.

Há que ser lembrado também que para os cristãos o primeiro sinal da paternidade socioafetiva foi a de Jesus com seu pai José, uma vez que mesmo biblicamente não haver relação sanguínea entre eles, a relação de paternidade existia.

Um dos requisitos exigidos para caracterização da filiação socioafetiva é a existência de posse de estado de filho, que segundo Orlando Gomes (1994, p. 331), seria:

\begin{abstract}
(...) ter de fato o título correspondente, desfrutar as vantagens a elas ligadas e suportar seus encargos. É passar a ser tratado como filho, que é identificado pela exteriorização da condição de filho nas seguintes circunstâncias: a) sempre ter levado o nome dos presumidos genitores; b) ter recebido continuamente o tratamento de filho; c) ter sido constantemente reconhecido, pelos presumidos pais e pela sociedade.
\end{abstract}

Sendo assim, com o advento da Constituição Federal de 1988, o estado de filho afetivo não é de posse e de domínio, mas sim de amor, de ternura, de respeito, de solidariedade, na busca da felicidade mútua, em cuja convivência não há mais nenhuma hierarquia.

Enquanto a família biológica navega na cavidade sanguínea, a família afetiva transcende os mares do sangue, conectando o ideal de paternidade e da maternidade responsável, hasteando o véu impenetrável que encobre as relações sociológicas, regogizandose com o nascimento emocional e espiritual do filho, edificando a família no condão umbilical do amor, do afeto, do desvelo, do coração e da emoção, (re) velando o mistério insoldável da filiação, engendrando um verdadeiro reconhecimento do estado de filho afetivo. (WELTER, p. 153)

E é por isso que se deve cuidar ao se falar de Direito e família, principalmente ao tratarse com menores, "pois atinge as pessoas nas fímbrias do seu coração e mexe com o que ela tem de mais íntimo e mais precioso em sua vida. É terreno que devemos sempre percorrer com extraordinário cuidado, como quem estivesse mexendo em cristais, para não criar fraturas". (BRASIL. TJRS, 1991) 
O provérbio popular "pai é quem cria” é o mais sábio de todos, pois pai não é apenas o genitor, mas, principalmente, protetor, amigo, enfim, aquele que apesar chegar em casa, cansado e com fome, antes de se alimentar ou descansar, "senta-se na beira da caminha, para contar mais um capítulo da história inventada, que não termina jamais, e que alimenta a fantasia de sua criança, numa linguagem de amor que ela entende bem”. (COMEL, 1998)

O amor também é um valor jurídico e disso decorre, como é óbvio, que a sua visualização na relação envolvendo os pais e aquele que é tratado como filho, independente do liame consanguíneo, vindo a produzir efeitos no tocante à consideração sobre a efetiva existência de relação paterno/filial entre os envolvidos nessa relação. (MACEL, 1986, p. 9294)

Primeiramente, no conceito social de paternidade não se incluía, necessariamente, o elemento biológico, o que somente veio a ocorrer mais tarde, por dois motivos psicológicos: “a) o ciúme, passando a exigir a exclusividade; b) o narcisismo, para rever-se o produto, levando o homem a exigir, como condição para tornar-se pai social, a convicção da paternidade biológica”. (ALMEIDA JUNIOR, 1940, p. 124)

Sendo assim, não se pode arquitetar diferença jurídica entre o filho biológico e afetivo, porquanto em ambos os casos são reconhecidos como filhos, os quais, perante a Constituição Federal de 1988, devem ser tratados de forma igual.

A Constituição Federal de 1988 (BRASIL, 1988) preconiza em seu Art. 227, § $6^{\circ}$ que:

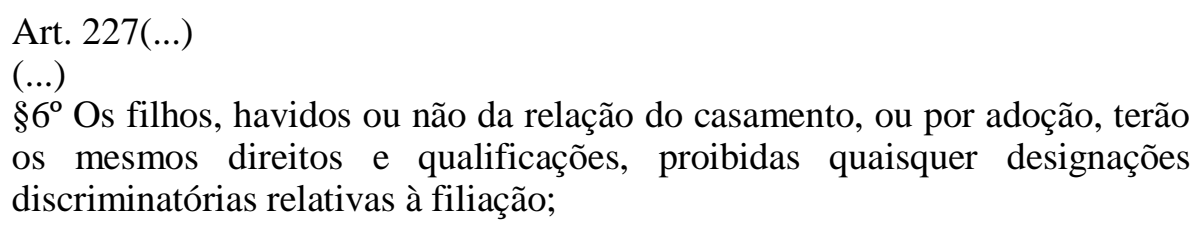

A igualdade no direito de filiação está assegurada também no art. 20 do Estatuto das Crianças e Adolescentes (BRASIL, 1990), bem como no art. 1596 do Código Civil (BRASIL, 2002), que estabelecem os mesmos direitos e qualificações entre filhos, proibidas quaisquer designações discriminatórias relativas à filiação. (LOMEU, 2015, p. 84)

Além da proteção no cambo legislativo da igualdade na relação familiar, a doutrina de Lomeu (2015, p. 84) assim informa: "Perante essa igualdade, consagrada está a máxima que não há hierarquias entre filiações, ou tipos de paternidade, seja biológica, afetiva ou civil. A paternidade tem como fundamento a afetividade, a convivência familiar e a vontade livre de ser pai". 
Quando se trava a discussão entre paternidade biológica e paternidade socioafetiva, restando estas caracterizadas, impositiva a sua prevalência sobre a outra.

Neste sentido existem alguns julgados.

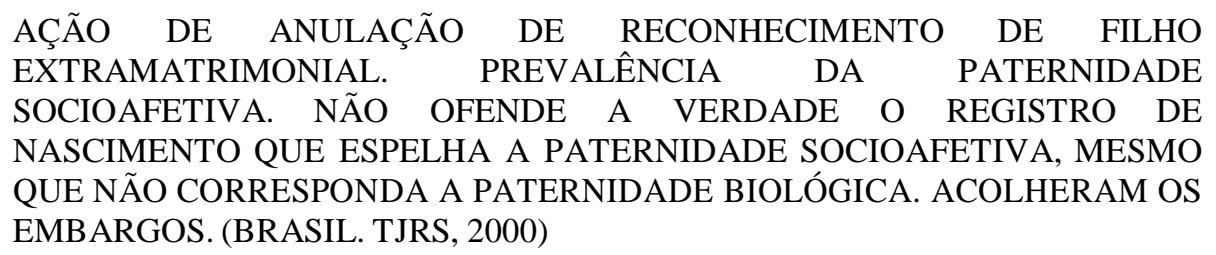

Percebe-se que a filiação socioafetiva é uma verdade que se impõe na realidade do direito atual frente à nova concepção da família que está voltada para valores afetivos.

Portanto,

(...) vale a pena notar que a paternidade afetiva pode distanciar-se da biológica para atender outros interesses em defesa da própria família que valoriza as relações afetivas entre seus membros, em busca de sua aspiração de felicidade. Isso gerou um novo modo de aprender as relações familiares e repercutiu no estabelecimento da filiação. Isso se explica no processo de passagem da família tradicional à família moderna, como resultado das transformações que implicaram a modificação de estruturas sociais, econômicas, políticas, e afetaram o próprio curso da história das sociedades. (FACHIN, 1992, p. 1524)

Destacados todos estes pontos, ainda cabe evidenciar mais uma jurisprudência sobre o tema, corroborando todos os pontos alegados e reforçando a temática sobre a socioafetividade familiar.

Logo, a paternidade socioafetiva é aquela relação entre pai e filho que ao longo do tempo vai criando raízes ao ponto de - apesar da verdade biológica - fazer criar uma outra verdade social que o Poder Judiciário não pode ficar alheio, uma vez que diz respeito à própria dignidade da pessoa humana, princípio que norteia todo sistema normativo. (Excerto do acórdão de BRASIL. TJRS. 2004.)

De tudo que foi exposto resta claro que a filiação socioafetiva possui valor jurídico e social, devendo ser respeitada tal qual a biológica, não podendo haver discriminações entre os filhos.

\section{ELEMENTOS CARACTERIZADORES DO ESTADO DE FILHO AFETIVO}

Três são os requisitos do estado de filho afetivo: "a nominatio, a tratactus e a reputatio (FACHIN, 1999, p. 202), ou seja, 'que a pessoa tenha sido tratada como filho do indigitado pai e que tenha, como tal, atendido a manutenção, à educação e à colocação dela; que a pessoa tenha constantemente considerado como filho nas relações sociais'”. (VELOSO, 1997, p. 33) 
A nominatio, que é o nome, é ter o filho o apelido do pai; a tractatus é ser tratado e educado como filho; e a reputatio é ser tido e havido por filho na família e na sociedade em que vive. (PONTES DE MIRANDA, 1917, p. 277)

Isso significa que o nome é o uso constante do apelido (sobrenome) da família do pai afetivo; o tratamento decorre do filho criado, educado, tido e apresentado à sociedade como filho; a fama ou reputação é a circunstância de ser sempre considerado, na família e na sociedade como filho.

Assim, o biológico estabelece que o marido da mãe é presumivelmente o genitor (autor genético da fecundação); o jurídico consagra que o marido da mãe é, por presunção, pai do filho da mulher com quem se casou, e o socioafetivo configura o marido da mãe que trata a criança por filho, enquanto este o enxerga como pai. (QUEIROZ, 2001, p. 49)

O fato a ser tomado pelo Direito como filiação não constitui apenas um fato biológico, mas também, um fato social, que se revela tanto na sua manifestação perante o grupo social, como especialmente, na esfera psicológica e afetiva dos sujeitos. (...) A verdade sociológica da filiação se constrói, revelando-se não apenas da descendência, mas no comportamento, quer em público, quer na intimidade do lar, com afeto verdadeiramente paternal, construindo vínculo que extrapola o laço biológico, compondo a base da paternidade. (FACHIN, 2004, p. 24-25)

Torna-se visível, portanto, a valorização do elemento socioafetivona relação pai e filho, pois a paternidade biológica se torna insuficiente se, ao mesmo tempo, não se encontrar a paternidade de afeto.

\section{IRREVOGABILIDADE DA FILIAÇÃO SOCIOAFETIVA}

Como já informado de maneira enfática alhures, a filiação socioafetiva tem força e não pode ser simplesmente desfeita.

Certamente há um viés ético na consagração da paternidade socioafetiva. Constituído o vínculo da parentalidade, mesmo quando desligado da verdade biológica, prestigia-se a situação que preserva o elo da afetividade. Não é outro o fundamento que veda a desconstituição do registro feito de forma espontânea por aquele que, mesmo sabendo não ser o pai consanguíneo, tem o filho como seu. (DIAS, 2009, p. 339)

Uma vez realizado esse registro, não há mais que se falar em revogação, assim é o assentamento da jurisprudência:

Quem sabendo não ser pai biológico, registra como seu filho de companheira durante a vigência da união estável, estabelece uma filiação sócio-afetiva, que 
produz os mesmos efeitos que a adoção, ato irrevogável. O pai registral não pode interpor ação negatória de paternidade e não tem legitimidade para buscar a anulação do registro de nascimento, pois inexiste vício material ou formal a ensejar sua desconstituição. (BRASIL. TJRS, 1999)

Pode-se também por analogia trazer-se o caso da filiação socioafetiva que surge com a adoção, sendo que esta também é irrevogável, conforme inteligência do artigo $39, \S 1^{\circ}$ do Estatuto da Criança e do Adolescente. ${ }^{1}$

Considerando que a Constituição Federal engendrou a unidade da filiação, assim como a irrevogabilidade da adoção, que é uma forma de filiação socioafetiva, conclui-se que a filiação sociológica também é irrevogável. Isso porque além de ter assento constitucional (arts. $226 \S \S 4^{\circ}, 7^{\circ}$ e $227, \S 6^{\circ}$ ), devem ser observados os princípios da prioridade e da prevalência absoluta dos interesses da criança e do adolescente, conforme art. 227, da Carta Magna, e arts. $1^{\circ}, 6^{\circ}, 15$ e 19 , entre outros, do Estatuto da Criança e do Adolescente. (WELTER, p. 193)

Assim, não há que se falar em revogação da filiação socioafetiva.

APELAÇÃO CÍVEL. AÇÃO NEGATÓRIA DE PATERNIDADE CUMULADA COM EXONERAÇÃO DE ALIMENTOS. ADOÇÃO À BRASILEIRA. O reconhecimento espontâneo da paternidade daquele que, mesmo sabendo não ser o pai biológico, registra como seu o filho da sua companheira, tipifica verdadeira adoção, irrevogável, descabendo, posteriormente, a pretensão anulatória de tal registro, por não demonstrado vício de consentimento. Improcedência da ação mantida. Apelação desprovida. (BRASIL. TJRS, 2004)

No confronto de tais interesses, há que prevalecer, sem qualquer margem de dúvida, os do menor, porquanto inserido numa realidade socioafetiva sem ter o direito sequer de opinar. É que, na aplicação da lei, a proteção aos interesses do menor sobrelevará qualquer outro bem ou interesse juridicamente tutelado.

\section{PROVAS A PRODUZIR PARA O RECONHECIMENTO DA FILIAÇÃO SOCIOAFETIVA}

Como em qualquer outro processo, a prova do estado de filho poderá ser produzida por todos os meios em direito admitidos, sendo possibilitado desta forma uma ampla gama de medidas a serem tomadas para a eventual comprovação da filiação.

${ }^{1} \mathrm{O}$ estatuto da criança e do adolescente, ECA, em seu artigo 39 informa que "A adoção de criança e de adolescente reger-se-á segundo o disposto nesta Lei.", de maneira mais precisa, no § 1o do mesmo artigo, a lei informa: “A adoção é medida excepcional e irrevogável, à qual se deve recorrer apenas quando esgotados os recursos de manutenção da criança ou adolescente na família natural ou extensa, na forma do parágrafo único do art. 25 desta Lei."

(BRASIL, 1990). 
Sendo assim, a prova deve versar acerca da publicidade desse estado de filho, eis que quando o fato é público, o estado de filho afetivo se consolida como verdadeiro reconhecimento da paternidade.

Assim, valor imensurável terá a prova testemunhal, a prova pericial, como estudo social e psicológico, bem como a prova documental com a prova pré-constituída da certidão de nascimento, além de: certidão de batismo; plano de saúde; inscrição no imposto de renda; Inscrição do filho afetivo em órgão previdenciário; concessão de caderneta de poupança; aplicações financeiras; testamento em favor de filho afetivo; fotografias que revelem a típica convivência familiar; escritura ou contrato de aquisição de imóvel ao filho ou em condomínio com os pais e filhos; bilhetes, cartas e cartões a indicar a filiação afetiva; seguro de vida beneficiando o filho; histórico escolar em que conste o nome dos pais afetivos como responsáveis; documentos das despesas de instrução e/ou médico hospitalar; qualquer documento em que conste o tratamento de filho, remessa de correio eletrônico (e-mail), denotando tratamento de filho; pagamento de pensão alimentícia; autorização para compra de mercadorias em casa comercial, em que é certificado o estado afetivo; o nome dos pais inscrito na roupa ou demais pertences do filho; depoimento pessoal em qualquer processo, reconhecendo a filiação afetiva; o nome do filho afetivo constando da certidão de óbito dos pais; os pais como responsáveis em consulta médica e/ou baixa hospitalar. (WELTER, p. 162).

Diante de tantos mecanismos diversos para a comprovação da filiação, é nítida a vontade social e jurídica para que seja devidamente comprovada a relação de pais e filhos, quer seja biologicamente, como ainda socioafetivamente.

Neste mesmo sentido, destaca-se em sequências quais são os fundamentos jurídicos no ordenamento pátrio, para que a filiação socioafetiva ocorra.

\section{PREVISÃO LEGAL DA FILIAÇÃO SOCIOAFETIVA NO ORDENAMENTO JURÍDICO}

A filiação socioafetiva pode ser encontrada em diversos artigos do Códex Civil, dentre eles se destaca o artigo 1593:

Art. 1593. O parentesco é natural ou civil, conforme resulte de consangüinidade ou outra origem.

O referido dispositivo classifica o parentesco, distinguindo os que resultam da consanguinidade dos que tenham outra origem. De acordo com a regra em exame, o parentesco civil é todo aquele que não tem origem biológica. O termo "outra origem", usado pelo 
legislador, admite como fontes de parentesco os casos de reprodução artificial e as relações socioafetivas, sem vínculo biológico. (CARVALHO FILHO, 2008)

Art. 1596. Os filhos, havidos ou não da relação de casamento, ou por adoção, terão os mesmos direitos e qualificações, proibidas quaisquer designações discriminatórias relativas à filiação.

Nesse artigo, portanto, é reafirmada a igualdade de filiação conforme preceito constitucional previsto no artigo 227, $\S 7^{\circ}$ da Constituição da República Federativa do Brasil de 1988.

Destaca-se que nesse diploma legal não existe sequer um dispositivo legal que privilegie a paternidade genética em detrimento da socioafetiva, ou que tenha cobrado do registro de pessoas naturais qualquer fidelidade aos fatos de biologia, pelo contrário, valoriza a igualdade e condena a discriminação.

Destaca-se também que a parentalidade socioafetiva é reconhecida no direito brasileiro no artigo 50 da Lei Maria da Penha (BRASIL, 2006), que considera como família "a comunidade formada por indivíduos que são ou se consideram aparentados, unidos por laços naturais, por afinidade ou por vontade expressa".

Fica bem claro, portanto, a existência de previsão legal acerca da existência e da validade da filiação socioafetiva, tanto na previsão do Código Civil que traz como possível parentesco 'outra origem', essa poderia, com toda certeza ser considerada como a socioafetiva; como também no artigo acima citado da Lei Maria da Penha que diz que a família é formada tanto pelos laços naturais, por afinidade ou por vontade expressa.

\section{USO do PATRONÍMio do PADRASTo OU DA MADRASTA - RECONHECIMENTO DE UMA PATERNIDADE/MATERNIDADE SOCIOAFETIVA}

Não há dúvidas que em vários casos os padrastos e as madrastas ${ }^{2}$ se encaixam em um papel de paternidade/maternidade socioafetivas, sendo que muitas vezes estão mais presentes do que os pais biológicos.

\footnotetext{
${ }^{2}$ Quanto a essas nomenclaturas que são utilizadas destaca-se doutrina de Maria Berenice Dias: "O fato é que não dispõe a língua portuguesa de uma palavra que permita ao filho identificar quem seja, por exemplo, o companheiro da mãe. Ninguém sabe como chamar o filho da mulher do pai. Também não há um vocábulo que permita distinguir o filho comum diante dos filhos de cada um do pai, frutos de relacionamentos anteriores. Claro que os termos madrasta, padrasto e enteado, assim as expressões filho da companheira do pai, ou filha do convivente da mãe e meio-irmão não servem, pois trazem uma forte carga de negatividade, resquício da intolerância social”. In: DIAS, 2009. p. 125. (grifo no original)
} 
A Lei 11.294/09 (BRASIL, 2009), chamada "Lei Clodovil", que modificou o artigo 57 da Lei 6.515, de 31 de dezembro de 1973 (BRASIL, 1973), Lei de Registros Públicos, veio trazer a possibilidade de inclusão do patronímico do padrasto ou madrasta.

A "Lei Clodovil" conduz à reflexões sobre famílias reconstituídas em que pelo menos um dos adultos é padrasto ou madrasta, ou exista pelo menos um filho de uma união anterior de um dos pais. Nesta categoria também se incluem tanto as sucessivas uniões de viúvos ou de viúvas, como de divorciados e divorciadas com filhos de uma relação precedente e as primeiras de mães e pais solteiros. (GRISARDO FILHO, 2007, p. 78-79)

Diz o referido artigo, in verbis:

Art. 57. A alteração posterior de nome, somente por exceção e motivadamente, após audiência do Ministério Público, será permitida por sentença do juiz a que estiver sujeito o registro, arquivando-se o mandado e publicando-se a alteração pela imprensa, ressalvada a hipótese do art. 110 desta Lei.

(...)

$\S 2^{\circ}$ A mulher solteira, desquitada ou viúva, que viva com homem solteiro, desquitado ou viúvo, excepcionalmente e havendo motivo ponderável, poderá requerer ao juiz competente que, no registro de nascimento, seja averbado o patronímico de seu companheiro, sem prejuízo dos apelidos próprios, de família, desde que haja impedimento legal para o casamento, decorrente do estado civil de qualquer das partes ou de ambas.

(...)

$\S 7^{\circ}$ Quando a alteração de nome for concedida em razão de fundada coação ou ameaça decorrente de colaboração com a apuração de crime, o juiz competente determinará que haja a averbação no registro de origem de menção da existência de sentença concessiva da alteração, sem a averbação do nome alterado, que somente poderá ser procedida mediante determinação posterior, que levará em consideração a cessação da coação ou ameaça que deu causa à alteração.

$\S 8^{\circ} \mathrm{O}$ enteado ou a enteada, havendo motivo ponderável e na forma dos $\S \S$ $2^{\circ}$ e $7^{\circ}$ deste artigo, poderá requerer ao juiz competente que, no registro de nascimento, seja averbado o nome de família de seu padrasto ou de sua madrasta, desde que haja expressa concordância destes, sem prejuízo de seus apelidos de família.

Percebe-se que para que esse registro ocorra, faz-se necessário que seja apresentado um "motivo ponderável”, haja concordância do padrasto ou da madrasta, bem como que o enteado(a) continue com seus apelidos de família, acrescendo então o apelido do padrasto ou da madrasta.

Esta possibilidade de alteração do nome decorre, portanto, dos princípios constitucionais de Dignidade da Pessoa Humana e da valorização do afeto. 
Afastado o preconceito legislativo em que pai e filhos independem de uma ligação biológica, o aspecto sociopsicológico, segundo uma visão ampla, liberta e democrática, assume gritante importância, acrescida da circunstância da dignidade da pessoa humana, adotada pelo constituinte como fundamento da república (CF, artigo $1^{\circ}$, III). (PEREIRA, 2010, p. 345)

Verifica-se que o "motivo ponderável" apresentado na legislação entende-se ser a existência de afeto entre o padrasto ou a madrasta com o enteado (a), que caracterize a paternidade/maternidade.

Destaca-se também, que a alteração do nome do enteado (a) em nada modifica a filiação biológica já existente, tanto que o registro do nome do pai ou da mãe biológicos será mantido.

Superadas essas premissas, verifica-se os pressupostos legalmente estabelecidos para que seja feito esse registro.

1. Requerimento judicial - a inclusão do nome do padrasto ou da madrasta só poderá se operar mediante a autorização judicial. Caberá ao magistrado, no caso concreto, tomando por base o atual conceito de família, avaliar acerca do cabimento da respectiva alteração nominal.

2. Expressa concordância do padrasto ou da madrasta - o patronímico do padrasto ou da madrasta só será incluído no nome do enteado uma vez verificada a concordância daqueles. Ora, se esta possibilidade de inclusão do nome de família decorre justamente do valor jurídico conferido ao afeto, é certo que ambas as partes envolvidas na questão deverão estar de acordo. O sentimento de amor não é (nem pode ser) unilateral.

3. Manutenção dos apelidos de família - A lei menciona que o nome de família do padrasto ou madrasta será incluído, sem prejuízo dos apelidos de família. $\mathrm{O}$ nome original da pessoa será mantido, havendo apenas um acréscimo. Os vínculos originários de filiação, não são, de modo algum, prejudicados.

4. Prazo de 05 anos (art. $57 \S 3^{\circ}$ ) - Para que possa ser incluído o nome do padrasto ou da madrasta, é imprescindível um período de convivência familiar de 05 (cinco) anos entre este e o enteado. Tal interpretação decorre da Lei dos Registros Públicos, que estabelece um prazo de 05 (cinco) anos para a averbação do registro de nascimento de conviventes e pessoas casadas e divorciadas.

5. Motivo ponderável - É requisito de ordem subjetiva, analisado sob o prudente arbítrio do juiz. Tal qual já se salientou, o afeto seria o principal motivo ponderável. Como postula Luciana Z. Mortari (2009), "ao que se lê, parece bastar a vontade livre e inequívoca das partes, bem como a ausência de qualquer vício que possa descaracterizar o pedido, critérios que deverão ser analisados no caso concreto. (PRETEL, 2010)

Há que se ponderar que a legislação trata somente da possibilidade de acréscimo do patronímico do padrasto ou da madrasta, mas não traz direito de filho ao enteado(a), inexistindo, 
então, qualquer direito sucessório ou alimentício entre eles, o que subsisti somente com relação aos pais registrais.

Existe entendimento de que seria possível excluir o nome do padrasto ou da madrasta com base no artigo 57, $\S 5^{\circ}$ da Lei dos Registros Públicos, sendo possível o cancelamento da averbação mediante o requerimento de uma das partes, ouvida a outra.

Logo, a lei admite o cancelamento da respectiva averbação. Entretanto, deve-se destacar que não foi esse o objetivo (a finalidade) da alteração do ordenamento jurídico ao possibilitar a inclusão do nome do padrasto ou madrasta. Em verdade, admitiu-se a paternidade socioafetiva e esta não poderia ser modificada a qualquer tempo pelas partes justamente em razão do afeto que a permeia. Tal paternidade ou maternidade não decorreria simplesmente de uma relação de casamento ou união estável entre o padrasto/madrasta e a mãe/pai, mas do elo de amor que justamente une aqueles ao enteado. A identidade existente entre as partes envolvidas não seria efêmera, passageira ou descartável. (PRETEL, 2010)

Deve ser lembrado, também, que desde 1997, com o Estatuto da Previdência Social, o enteado ou enteada equipara-se a filho para fins previdenciários, mediante a comprovação da dependência econômica (art. 12, § $2^{\circ}$ da Lei 8.213/1991, redação dada pela Lei 9.258/1997), portanto o enteado pode ter direitos previdenciários.

Percebe-se que essa legislação veio valorizar os laços de amor e de afeto que existem entre os enteados e seus padrastos e madrastas.

\section{CONSIDERAÇÕES FINAIS}

A filiação socioafetiva não é algo novo, ela sempre existiu no seio familiar, como no caso da adoção ou nas inseminações artificiais heterólogas enfim, desde o nascimento de Jesus para os cristãos.

Um dos requisitos, portanto, para a caracterização da filiação socioafetiva é a existência de posse do estado de filho que seria ter de fato o título correspondente, desfrutando das vantagens a ele ligadas, bem como suportando seus encargos.

Assim, considerando a existência e a validade da filiação socioafetiva, não há que se falar na possibilidade de tratamento desigual desse filho ante o previsto no artigo $227, \S 6^{\circ}$, da Constituição da República Federativa do Brasil de 1988, como também do previsto no artigo 
20 do Estatuto da Criança e do Adolescente, e no artigo 1.596 do Código Civil.

Para caracterização, então, do estado do filho afetivo há que se observar três critérios importantes: o nome, ou seja, o filho ter o apelido do pai; ser tratado e apresentado como filho; e por fim, ter a fama e reputação de ser sempre considerado, na família e na sociedade como filho.

Portanto, uma vez caracterizada a filiação socioafetiva esta é irrevogável como acontece no caso das adoções.

No ordenamento jurídico brasileiro destaca-se que nos artigos 1.593 e 1.596, ambos do Código Civil, e no artigo 50 da Lei Maria da Penha, já existe previsão desse tipo de filiação.

A Lei 11.924/2009, que possibilita ao enteado (a) acrescentar o patronímico do padrasto ou da madrasta, deu um passo significativo ao concretizar no âmbito legal a socioafetividade nas relações familiares. Esta lei, também chamada de "Lei Clodovil", valoriza a filiação socioafetiva.

\section{REFERÊNCIAS BIBLIOGRÁFICAS}

ALMEIDA JÚNIOR, A. Paternidade: aspectos bio-psicológico, jurídico e social. São Paulo: Companhia Editora Nacional, 1940.

BRASIL. Constituição da República Federativa do Brasil de 1988. Brasília, Poder Constituinte Originário, 1988.

. Lei 6.515, de 31 de dezembro de 1973. Brasília: Congresso Nacional, 1973.

Lei 8.069 de 13 de julho de 1990. Congresso Nacional, 1990.

. Lei 10.406 de 10 de janeiro de 2002. Congresso Nacional, 2002.

. Lei 11.294, de 17 de abril de 2009. Brasília: Congresso Nacional, 2009.

Lei 11.340, de 7 de agosto de 2006. Brasília: Congresso Nacional, 2006.

. TJRS. Ac. 4 Grupo do TJRS, em 09.08.1991. Relator Desembargador Luiz Melíbio Uiraçaba Machado. RJTJRS, acerca da divergência doutrinária e jurisprudencial sobre a união estável. 
TJRS. Oitava Câmara Cível. Agln 70010214476. Relator Desembargador Rui Portanova. Julgado em 23.12.2004.

. TJRS. Quarto Grupo de Câmaras Cíveis. Embargos Infringentes n⿳0 70000904821.

Relator: Luiz Felipe Brasil Santos. Julgado em 10/11/2000.

CARVAlHO FILHO, Paulo de. Código Civil comentado: doutrina e jurisprudência. Coord. Ministro Cezar Peluso. 2. Ed. Barueri: Manole, 2008.

COMEL, Nelsinha Elizana Damo. Paternidade responsável: o papel do pai na sociedade brasileira e na educação familiar. Curitiba: Juruá, 1998.

DIAS, Maria Berenice. Manual de direito das famílias. São Paulo: Editora Revista dos Tribunais, 2009.

FACHIN, Edson Luiz. Comentários ao novo código civil, volume XVIII: do direito de família, do direito pessoal, das relações de parentesco. Rio de Janeiro: Forense, 2004.

. Elementos críticos do direito: Curso de direito civil. Rio de Janeiro: Renovar, 1999.

. Estabelecimento da filiação e paternidade presumida. Fabris. 1992.

GOMES, Orlando. Direito de família. 7. ed. Rio de Janeiro: Forense, 1994.

GRISARDO FILHO, Waldyr. Famílias reconstituídas nas uniões depois das separações. São Paulo: Ed. RT, 2007.

LOMEU, Leandro. Reconhecimento voluntário de paternidade socioafetiva. Revista Síntese. Direito de Família. São Paulo; Síntese, fev/março/2015.

MACEDO, Silvio de. Curso de axiologia jurídica. Rio de Janeiro: Forense, 1986.

PEREIRA, Rodrigo Cunha. Princípios fundamentais norteadores do direito de família. Belo Horizonte: Del Rey, 2006.

PONTES DE MIRANDA, Francisco Cavalcanti. Direito de Família: exposição technica e systeatica do Código Civil brasileiro. Rio de Janeiro: Jacintho Ribeiro Santos, 1917.

PRETEL, Mariana Pretel e. Lei no 11.294/09: a possibilidade de inclusão do nome do padrasto ou madrasta. Revista Jus Navigandi, Teresina, ano 15, n. 2389, 15 jan. 2010. Disponível em: 
<http://jus.com.br/artigos/14189>. Acesso em: 30 jul. 2015.

QUEIROZ, Juliane Fernandes. Paternidade: aspectos jurídicos e técnicos de inseminação artificial. Belo Horizonte: Del Rey, 2001.

VELOSO, Zeno. Direito brasileiro da filiação e paternidade. São Paulo: Malheiros, 1997.

VILLELA, João Baptista. Repensando o direito de família. In: Nova realidade do direito de família. Rio de Janeiro: COAD, t.2, SC Editora Jurídica, 1999.

WELTER, Belmiro Pedro. Igualdade entre as filiações biológica e socioafetiva. São Paulo: Revista dos tribunais. 